Z. Klin. Chem. Klin. Biochem.

12. Jg. 1974 , S. $357-360$

\title{
A Method for the Quantitative and Qualitative Determination of the Total Long Chain Fatty Acids in Urine
}

\author{
By A. Christophe, R. Geers and G. Verdonk
}

\author{
Laboratory of Gerontology, Dietetics and Nutrition Research (Director: Prof. Dr. G. Verdonk) State University of \\ Ghent, Belgium
}

(Eingegangen am 14. Dezember 1973/7. Mai 1974)

\begin{abstract}
A method is described for the identification and quantitative determination of the urinary long chain fatty acids.
The urinary lipids are saponified, the unsaponifiable fraction is removed, the fatty acids are extracted after acidification and converted into methyl esters. These are purified by thin layer chromatography and analysed by gas liquid chromatography. The eluted components are identified on basis of their chromatographic behavior in three different chromatographic systems.
\end{abstract}

Eine Methode zur Identifikation, Quantitation, Bestimmung und Feststellung des Fettsäuremusters der langkettigen Fettsäuren im Urin wird beschrieben.

Die Urin-Lipide werden verseift, der nicht verseifbare Anteil abgetrennt, die Fettsäuren nach Ansäuern extrahiert und in ihre Methylester umgesetzt. Diese werden durch Dünnschichtchromatographie gereinigt und gaschromatographisch bestimmt. Die Identifizierung der eluierten Komponenten erfolgt auf Grund ihres chromatographischen Verhaltens in drei verschiedenen Systemen.

It has been shown that several lipid classes are present in normal urine $(1,2)$. It has been proposed that the non esterified fatty acid fraction is of physiological significance (3). Increases of some of these acids has been noted in pathological urines $(1,4)$. The increase of the total fats has been associated with the nephrotic syndrome (5), with fat embolism (6) and with alcoholism (7), that of the triglycerides and cholesteryl esters with nephrosis (8), that of the free fatty acids with albuminuria (8) and that of the glycolipids with Fabry's disease (9) and with metachromatic leukodystrophy (10). In view of these findings we decided to develop a method for the estimation of the total urinary long chain fatty acids and for the determination of their pattern.

\section{Materials and Methods}

\section{Reagents}

All reagents were Merck pro analysi products except the lipid standards and the support and liquid phases for gas chromatography which were obtained from Applied Science Laboratories (College Station, U.S.A.).

A pentadecanoic acid solution in isooctane $(100 \mathrm{mg} / \mathrm{l})$ was used as internal standard.

The water used was deionised and distilled.

All glassware and filter paper were washed consecutively three times with chloroform/MeOH ( $2 / 1$ by volume) and twice with petroleum ether (b.p. $40^{\circ}-60^{\circ} \mathrm{C}$ ).

\section{Thin-layer plates}

A slurry of $50 \mathrm{~g}$ silica gel $\mathrm{H}$ in $110 \mathrm{ml} 0.01 \%$ aqueous rhodamine $6 \mathrm{G}$ solution is spread out on $200 \times 200 \mathrm{~mm}$ glass plates to a thickness of $0.25 \mathrm{~mm}$. After air drying for at least $24 \mathrm{~h}$, the plates are ready for use.

Analytical gas chromatographic system

Two glass columns, length $2 \mathrm{~m}$, I.D. $2 \mathrm{~mm}$, packed with $5 \%$ polymer EGSS-X on Gas-Chrom Q 80-100 mesh, are installed in a Hewlett Packard gas chromatograph, model $5720 \mathrm{~A}$, equipped with flame ionisation detectors. One column is used for analysis, the other one for base line compensation.

\section{Identification system}

A $2 \mathrm{~m}$ glass column, I.D. $2 \mathrm{~mm}$, packed with $5 \%$ polymer EGSS-X on Gas-Chrom Q 80-100 mesh and a $1 \mathrm{~m}$ glass column, I.D. $4 \mathrm{~mm}$, packed with $1 \%$ UCW on Gas-Chrom $Q$ 80-100 mesh are placed in an F \& $\mathrm{M}$ gas chromatograph, model 402, equipped with two flame ionisation detectors, a double electrometer and a double pen recorder. The carrier gas flow $\left(\mathrm{N}_{2}\right)$ of the polar column (EGSS-X) is adjusted to obtain optimal separation (11); that of the apolar one (UCW) is adjusted so that methyl oleate is eluted with the same retention time on both columns.

Urines

After collection, all urine specimens are stored in a refrigerator at $4^{\circ} \mathrm{C}$. Before analysis, all collections made during a $24 \mathrm{~h}$ period are pooled. Urine can be stored for at least one week at $4^{\circ} \mathrm{C}$ without changes in total fatty acid concentration or pattern.

Preparation of a total fatty acid extract

Add to a fraction of shaken urine (e.g. $100 \mathrm{ml}$ ) the same volume of a saturated $\mathrm{KOH}$ solution in $95 \%$ ethanol. Reflux the mixture for about $30 \mathrm{~min}$ under nitrogen, cool to about $40^{\circ} \mathrm{C}$ and remove the unsaponifiable material by three consecutive extractions with petroleum ether (b.p. $60^{\circ}-80^{\circ} \mathrm{C}$ ). Acidify the aqeous phase with concentrated hydrochloric acid to about $\mathrm{pH} 1$ and extract it three times with petroleum ether 
(b.p. $40^{\circ}-60^{\circ} \mathrm{C}$ ). Dry the pooled petroleum ether extracts over anhydrous $\mathrm{Na}_{2} \mathrm{SO}_{4}$, filter and concentrate with a flash evaporator under vacuum to a few $\mathrm{ml}$ at a temperature not exeeding $40^{\circ} \mathrm{C}$.

Transfer quantitatively to a volumetric flash and make up to volume (petroleum ether).

\section{Preparation and purification of methyl esters}

Add an appropriate amount (see discussion) of the internal standard solution to a fraction of the total fatty acid extract and convert the total fatty acids into methyl esters (e.g. 12, $13,14)$.

Concentrate the methyl ester solution to about $0.1 \mathrm{ml}$ and transfer it quantitatively to one half of a thin layer plate (methyl heptadecanoate is spotted on the other half as an indicator for the methyl esters). Develop the plate with petroleum ether (b.p. $60^{\circ}-80^{\circ} \mathrm{C}$ )/acetone $(85 / 15$ by volume) for about $100 \mathrm{~mm}$, dry the plate in a nitrogen atmosphere and develop again with hexane for about $170 \mathrm{~mm}$. Dry the plate under nitrogen, scrape off the methyl ester band (which is visible under daylight and even more so under ultra violet light) into a test tube containing $3 \mathrm{ml}$ of petroleum ether (b.p. $40^{\circ}-60^{\circ} \mathrm{C}$ ), add $2 \mathrm{ml}$ of $\mathrm{MeOH} / \mathrm{H}_{2} \mathrm{O}(1 / 1$ by volume) remove the petroleum ether phase, extract twice more with $2 \mathrm{ml}$ petroleum ether (b.p. $40^{\circ}-60^{\circ} \mathrm{C}$ ) and dry the pooled petroleum ether extracts over anhydrous $\mathrm{MgSO}_{4}$.

\section{Gas chromatography}

Inject $1 \mu l$ of the concentrated methyl ester solution into the analytical gas chromatographic system. Program column temperature from $80^{\circ} \mathrm{C}$ to $200^{\circ} \mathrm{C}$ at a rate of $6^{\circ} / \mathrm{min}$ and hold constant for $30 \mathrm{~min}$ at $200^{\circ} \mathrm{C}$. Injector and detector temperature are held constant at $250^{\circ} \mathrm{C}$.

Calculate the percentage composition of the total fatty acids (12) and the amount of each fatty acid from the area of the corresponding methyl ester peak, the area of the internal standard peak and the amount of the internal standard added (12). Eventually, characterisation and identity confirmation of the components can be done by injecting immediately after each other $1 \mu$ l of the methyl ester solution on the apolar and $1 \mu$ l on the polar column of the identification system. (Column temperature programmed from $80^{\circ} \mathrm{C}$ to $200^{\circ} \mathrm{C}$ at $5^{\circ} \mathrm{C} / \mathrm{min}$ and held constant at the upper limit till all components are eluted; temperature of injection port and detector held constant at $250^{\circ} \mathrm{C}$ ). Comparison of elution temperatures of the unknown components on both columns with those of standards can eventually lead to identification; in any case, comparison of equivalent chain lengths on both columns gives valuable structural information about the unknown component $(15,16)$.

An identification chromatogram of the total fatty acids from urine of a nephrotic patient is shown in Figure 1.

\section{Results}

Good chromatograms are obtained with the method described, even for urine samples with the lowest amounts of total fatty acids (normal urines; $10 \mathrm{mg} / 1$ total fatty acids (Fig. 2 bottom). Qualitative and quantitative results are reproducible, the standard deviation on the percentage composition changing from $5 \%$ for big peaks in the chromatogram to $10 \%$ for small peaks, that on the quantitative results being about $6 \%$. As to the accuracy, it was found that fatty acids added to urine as trilinolein, monoolein, margaric acid or $L-\alpha$ dilinoleoyl lecithin in $\mathrm{CHCl}_{3}-\mathrm{MeOH} 2 / 1$ (by volume) solution were recovered quantitatively; the amount of fatty acids obtained by saponification was never lower (but usually higher) than that obtained by direct esterification - transesterification (12) of a total

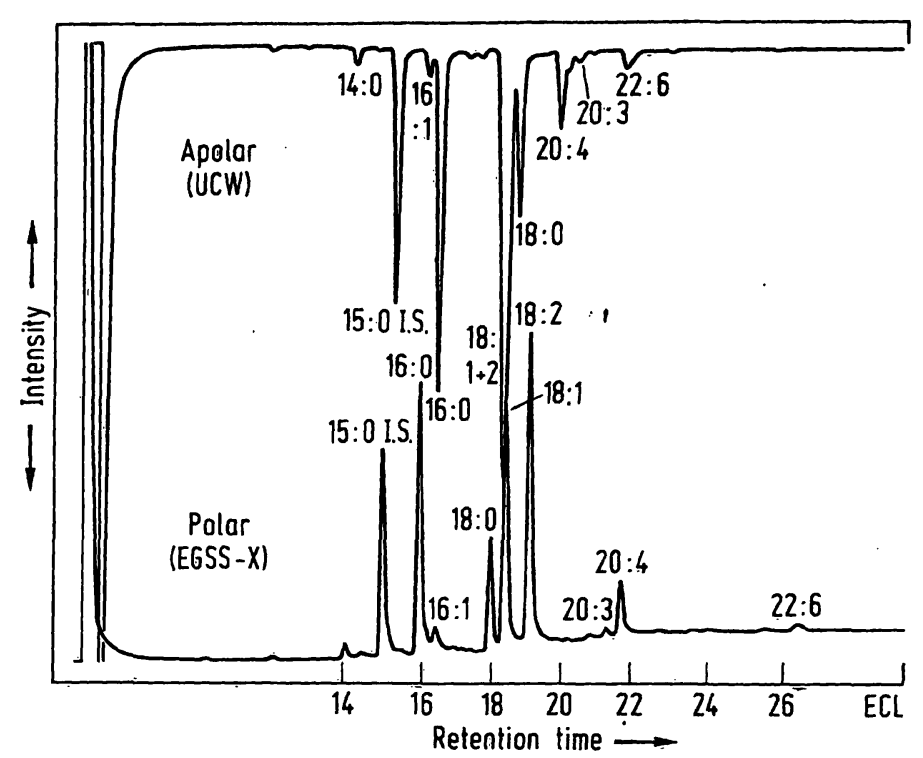

Fig. 1. Identification chromatogram of nephrotic urine total fatty acids. Working conditions in text.

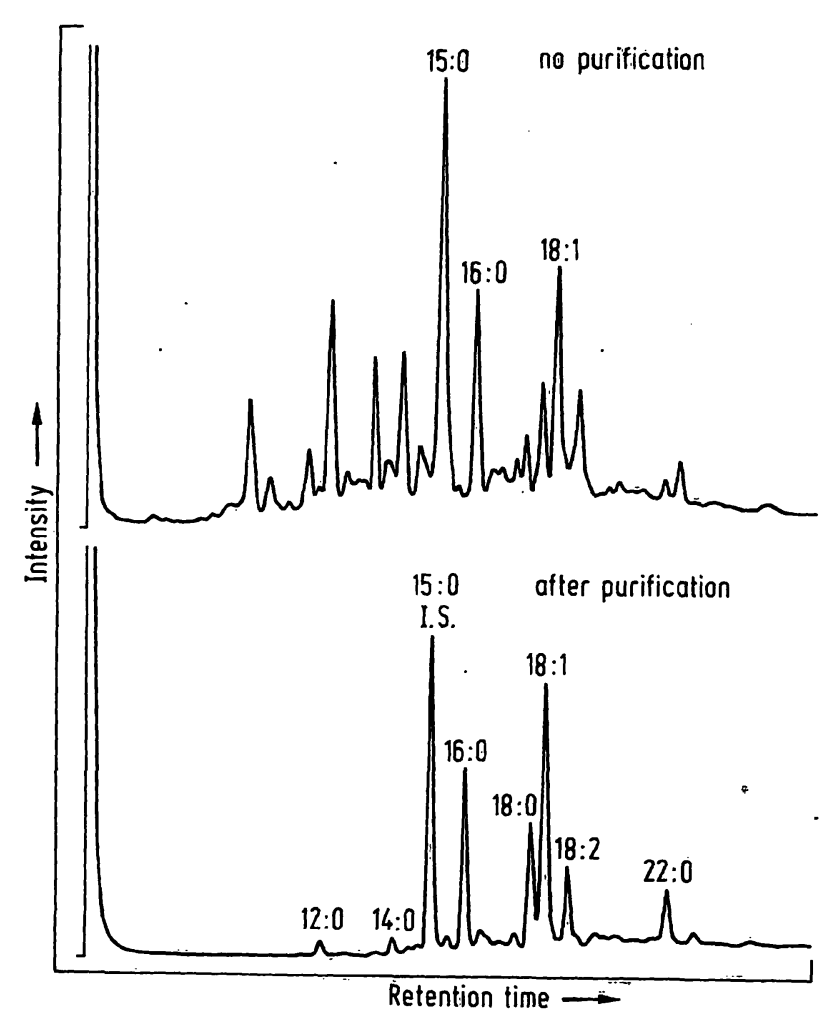

Fig. 2. Analytical gas chromatogram of not purified (top) and thin layer purified (bottom) methyl esters prepared from normal urine. Working conditions in text.

Folch lipid extract (17) and identical results were obtained by direct esterification-transesterification (12) of a Folch lipid extract (17) and by direct esterificationtransesterification of a lyophilised sample. These results indicate that the long chain fatty acids are recovered quantitatively. Quantitative recovery of linoleate, added as triglyceride or as lecithin indicates that no oxidative losses of unsaturated fatty acids occur. 
Results obtained with this method on normal and pathological urines are described elsewhere $(1,8)$.

\section{Discussion}

The optimal amount of internal standard to be added is the same as the amount of the major fatty acid present in the urine sample and this should be determined by a trial experiment. For a $100 \mathrm{ml}$ urine sample $1 \mathrm{ml}$ of standard solution for normal urine and $1 \mathrm{ml} \mathrm{per} \mathrm{g} / \mathrm{l}$ protein for protein-containing urine is a suitable estimate for the trial experiment (8).

Pentadecanoic acid is suitable as internal standard, as it was found to be present in urine only in minute quantities.

Extraction of the saponified urine with petroleum ether from alkaline medium is not necessary, but preferable; this treatment removes components which otherwise react during the esterification step to form derivatives with the same $R_{F}$ value in the thin layer system as methyl esters and which are eluted in the gas chromatographic systems with very long retention times, thus increasing analysis time unnecessarily. The extraction is best done at $40^{\circ} \mathrm{C}$ to facilitate separation of phases and to avoid emulsion formation.

Thus, for this extraction step, petroleum ether with a boiling point range $60^{\circ}-80^{\circ} \mathrm{C}$ is indicated; for the other extraction steps, the more volatile petroleum ether fraction b.p. $40^{\circ}-60^{\circ} \mathrm{C}$ is prefered.

By direct esterification - transesterification (12) of the petroleum ether extract from the alkaline medium to which an internal standard was added, it was shown that no fatty acids could be recovered from it, indicating that this extraction does not lead to losses of urinary long chain fatty acids.

Extraction of the long chain fatty acids from acid medium often results in the formation of rather stable emulsions. In general, these emulsions cannot be avoided by working at higher temperatures but they can be avoided by changing the composition of the aqueous phase, by addition of water or of $\mathrm{MeOH}$. Usually, the best results are obtained when the polar phase is composed of alcohol/water in a ratio of $1 / 1$ (by volume). Low speed centrifigation may be required to break the emulsions.

In order to check the recovery of long chain fatty acids from urine, an internal standard was added to the extracted aqueous phase which was brought to dryness by azeotropic distillation with benzene/ $\mathrm{MeOH}(1 / 1$ by volume) under vacuum (18) or by lyophilisation. The amount of fatty acids in this dried sample was determined by gas chromatography after direct esterification - transesterification (12). For all the samples examined, it was found that about $1 \%$ of the total fatty acids were not recovered from the aqueous phase. It could not be ascertained whether these fatty acids were present in a water-soluble form in the aqueous phase, or merely not completely extracted.

The finding that the non extracted fatty acids have the same fatty acid composition as the extracted ones suggest the latter supposition. Since only $1 \%$ of the total fatty acids is not recovered, the extraction of these can be considered quantitative for all practical purposes.

It was found that all extracts could be stored deep frozen $\left(-20^{\circ} \mathrm{C}\right)$ for at least three months.

In addition to the long chain fatty acids, the extract contains other material which gives rise to components that interfere with the gas chromatographic determination of the methyl esters. The amount of interfering material is about constant ${ }^{1}$ ), interference thus being the more important the lower the amount of fatty acids in the urine.

The interfering components can be effectively eliminated by thin layer purification of the methyl esters, as can be seen from Figure 2. The methyl esters of normal or branched long chain saturated or unsaturated fatty acids move as one component in the thin layer chromatographic system and thus, eventually, they are recovered for gas chromatography; methyl esters of hydroxy acids, keto acids or medium chain fatty acids have other $R_{F}$ values and are not recovered.

The identification of the components (identification system) is based on the combination of their elution characteristics on a polar and non polar column $(15,16)$.

When components have the same retention time and peak widths as methyl ester standards on each column of the identification system, they can be considered as identical with the standards, having the same chromatographic behavior in three different chromatographic systems.

Usually, the same fatty acids (but in different proportions) are present in urine as in serum. In one urine sample from a patient with glomerulonephritis, 10-hydroxystearic acid which is not present in serum, was identified in the urine (4).

The method yields information on the total fatty acids which are present in urine, irrespective of whether they are free, protein bound or incorporated in cellular material.

In normal urine the major part of the fatty acids is not incorporated in cellular material and is not bound;

\footnotetext{
1) The amount of material in the extract can be estimated by acid-dichromate oxidation (19). It was found that the fatty acids in the extract, as determined by gas chromatography, accounted for 20 to $70 \%$ of the reduction of the dichromate, the contaminating material from 11 urine having a reducing capacity equivalent to that of 50 to $120 \mathrm{mg}$ palmitic acid (range found for 23 urine samples of normal persons and patients with different diseases).
} 
identical results are obtained for the amount and composition of the fatty acids with or without centrifugation of the urine, and the amount of protein is too small to bind more than a small fraction of the fatty acids ${ }^{2}$ ). Evidence has been presented that the major fraction of total fatty acids of normal urine are not esterified, and they are probably derived by glumerular filtration of the serum non protein bound free fatty acid anions $(3,8)$.

$\left.{ }^{2}\right)$ Normal urine does contain small amounts of protein (upper limit normal range about $200 \mathrm{mg} / \mathrm{l}(20)$. Assuming all this protein is glomerular filtered serum albumin, which is certainly an overestimation - the amount of fatty acids bound to it would be $200 \mathrm{mg} / 1 \times \frac{20}{4000}=1 \mathrm{mg} / 1(200 \mathrm{mg} / 1$ serum free fatty acids and $40,00 \mathrm{~g} / \mathrm{l}$ serum albumin) or about $10 \%$ of normal urine total fatty acids. Moreover, if a major portion of urinary fatty acids were excreted as free fatty acid-albumin complex, there would be a strong resemblance between urinary and serum free fatty acid composition, and this was shown to be not the case (8).

\section{References}

1. Christophe, A. \& Verdonk, G. (1971), Arch. Intern. Physiol. Biochim. 79, 1013-1014.

2. Fox, I. S., Devor, A. W. \& Devor, K. A. (1971), Clin. Chem. 17, 519-524.

3. Hagenfeldt, L. (1971), Clin. Chim. Acta 32, 471-474.

4. Christophe, A. \& Verdonk, G. (1972), Abstracts 11 th World Congr. Intern. Soc. Fat Research, Göteborg, p. 51-52.

5. Laudat, M. H. \& Laudat, P. (1968), Rev. Franç. Etudes Clin. Biol. 13, 168-172.

6. Adler, F., Peltier, L. F., and Lai, S. P. (1960), Surgery (St. Louis) 47, 959-962.

7. Broder, G. (1969), Lancet $I I, 188-189$.

8. Christophe, A. \& Verdonk, G. (1973), in "Protides of the Biological Fluids" (H. Peeters, ed.) p. 555-559, Pergamon Press, New York.

9. Gregoire, P. E., Jonniaux, G. \& Voet, W. (1971), Clin. Chim. Acta, 33, 387-394.
In proteinuria, there usually is an increase in total urinary fatty acids (8). An hyperbolic correlation was found to exist between the amount of total fatty acids relative to the amount of proteins and the amount of protein (8).

In histuria, the major part of total fatty acids in urine may originate from cellular lipids, in chyluria, from lymph lipids a.s.o.

Wherever the fatty acid composition and or the quantity of urinary total fatty acids deviates from normal, further fractionation of the urine (centrifugation, dialysis, ultrafiltration) (1) or of the urinary lipid classes (8) might be considered.

\section{Acknowledgements}

The authors are indebted to the Nationaal Fonds voor Wetenschappelijk Geneeskundig Onderzoek for financial support and to the Nationaal Centrum voor Wetenschappelijke en Technische Documentatie for literature study.
10. Wherett, J. R. (1967), Clin. Chim. Acta 16, 135-145.

11. Christophe, A., (1971), Intern. Symp. Chromatogra. Electrof. 6, 65-72.

12. Matthys, F., Christophe, A. \& Verdonk, G (1972), Clin Chim. Acta, 36, 341-350.

13. Klopfenstein, W. E. (1971), J. Lipid Res. 12, 773-776.

14. Metcalfe, L. D. \& Schmitz, A. A. (1961), Anal. Chem $33,363-364$.

15. Miwa, T. K., Mikolajeczak, K. L., Earle, F. R. \& Wolff, I. A. (1960), Anal. Chem. 32, 1739-1742.

16. Miwa, T. K. (1963), J. Amer. Oil Chem. Soc. 40, 309-313.

17. Folch, J., Lees, M., and Sloane-Stanley, G. H. (1957), J. Biol. Chem. 226, 497-509.

18. Kahane, E. (1966), Rev. Roum. Biochim. 3, 73-79.

19. Pande, S. V., Khan, R. P., and Venkitasubramanian, T. A (1963), Anal. Biochem. 6, 415-423.

20. Hemmingsen, L. (1972), Clin. Chim. Acta 36, 185-188.

Dr. A. Christophe Laboratory of Gerontology Dietetics and Nutrition Research State University of Ghent

Pasteurlaan 2 B-9000 Ghent Belgium 